\title{
LA FIGURA NATURAL EN RIESGO. IMPLICACIONES DE LA CRISIS ECOLÓGICA PARA LA ESTÉTICA TEOLÓGICA
}

\author{
LUCIO FLORIO \\ Pontificia Universidad Católica de Argentina
}

\begin{abstract}
RESUMEN: La crisis medioambiental está generando una modificación vertiginosa en la biosfera (sexta extinción masiva de especies, modificación climática, contaminación de aguas y aire, urbanización desmedida, etc.). Este cambio produce, a su vez, una ruptura en la percepción de la naturaleza tal como ha existido hasta el siglo XIX, donde todavía quedaban territorios relativamente intocados.

Desde la teología de tradición bíblica, la creación ha sido considerada no sólo como un camino hacia el Creador sino incluso como el primero de los hechos salvíicos, con el que se ha inaugurado la historia de la salvación. La tradición patrística y mística cristianas han desarrollado la idea de que la naturaleza es un camino de encuentro entre el creyente y su fuente. Sin embargo, la situación en la que la biosfera ha ingresado en las últimas décadas pone en riesgo la percepción de la figura natural como un «tú» mediador autónomo en el encuentro con la figura divina.
\end{abstract}

PALABRAS CLAVE: naturaleza; ecología; estética teológica; figura; percepción.

\section{The natural figure at risk. Implications of the ecological crisis for the theological aesthetics}

ABSTRACT: The environmental crisis is generating a vertiginous change in the biosphere (sixth mass extinction of species, climate change, water and air pollution, excessive urbanization, etc.). This change produces, in turn, a break in the perception of nature as it has existed until the nineteenth century, where there were still relatively untouched territories.

From the theology of biblical tradition, creation has been considered not only as a path to the Creator but also as the first of the soteriologic events of salvation, which inaugurated the history of salvation. Patristic tradition and Christian mysticism have developed the idea that nature is a way of encounter between the believer and its source. However, the situation in which the biosphere has entered in recent decades threatens the perception of the natural figure as a "you», mediator in the encounter with the divine figure.

KEY WORDS: nature; ecology; theological aesthetics; figure; perception.

\section{INTRODUCCIÓN}

La crisis medioambiental está generando una alteración vertiginosa en la biosfera, cuyas expresiones más importantes son la extinción masiva de especies - probablemente, la sexta en la historia de la vida-, el cambio climático, la contaminación de aguas y aire y la urbanización desmedida. Esto está produciendo problemas que afectan a la subsistencia del conjunto de la biosfera y del mismo ser humano. Por otra parte, hay también una alteración en la percepción humana del ámbito en el que habita debido a la modificación radical de la naturaleza. En efecto, la alteración global de las relaciones ecológicas repercute en la percepción de la naturaleza tal como ha existido hasta hace relativamente poco tiempo, donde todavía quedaban territorios sin 
perturbaciones antrópicas. En nuestro tiempo, la naturaleza no aparece como un misterioso reducto de formas, belleza y recursos, sino como un amenazante y empobrecido territorio que reacciona en modos inimaginables.

Asimismo, la percepción religiosa de la naturaleza está cambiando de manera acelerada. Ahora bien, desde el pensamiento de tradición bíblica, el mundo ha sido considerada no sólo como un camino hacia el Creador sino incluso como el primero de los hechos salvíficos, con el que se ha inaugurado la historia de la salvación. La tradición patrística y mística cristianas han desarrollado la idea de que la naturaleza es un camino de encuentro entre el creyente y su fuente. Sin embargo, la situación en la que la biosfera ha ingresado en las últimas décadas pone en riesgo la percepción de la figura natural como un mediador en el encuentro con la figura divina.

Lo que se intenta describir en el presente texto es la situación de la estética de la naturaleza en una perspectiva teológica en el tiempo del Antropoceno. En otras palabras, la reflexión sobre la percepción de la naturaleza, desde una mirada bíblicamente focalizada, en un período en que la naturaleza inmediata al ser humano sufre una transformación profunda, precisamente por acción del mismo hombre.

\section{LA FIGURA NATURAL}

En la perspectiva bíblica, la naturaleza aparece como el primero de los hechos salvíficos (cfr. Sal 74; 111), como una creación de Dios que preludia y acompaña a la del ser humano (Gn 1,2-2, 4a), como signo de la gloria y del poderío divino (cfr. Sal 18; 104), inclusive en el absurdo del sufrimiento (cfr. Job 38,4-7). Pero también es camino hacia el Dios creador (Sab 13, 1-9, Rom 1, 19-20), rastro de su sabiduría y belleza (cfr. Sal 97; 104) y, en el ámbito del NT, reflejo del Logos creador (cfr. Jn 1,14), sujeto de liberación por Cristo (Rom 8, 19-22), partícipe del destino escatológico (Ib.).

Interesa aquí situar el tema de la naturaleza desde la perspectiva estética que, siguiendo la estela bíblica, se desarrolló por buena parte de la patrística, en el seno de la teología, la espiritualidad y la literatura cristianas; algo que Hans Urs von Balthasar sistematizara en su Estética Teológica ${ }^{1}$. En esta obra, el autor suizo considera que la primera actividad del creyente es perceptiva: se trata de captar la figura teológica que emerge en el horizonte mundano. "Figura» (Gestalt) es para von Balthasar la presencia sensible en el campo perceptivo de la gloria (kabod, doxa) divina². Dicha manifestación se produce de manera inicial en el mundo natural, aunque es desde la aparición de la figura cristológica

1 Von Balthasar, H. U., Gloria. Una estética teológica. T. 1: La percepción de la forma, Cristiandad, Madrid 1985. Cf. también: IB., «El lenguaje de Dios», Proyecto, 30 (1998) 43-69.

2 Vignolo, R., H.U.von Balthasar: Estetica e singolarità, Istituto Propaganda Libraria, Milano, 1982, 487. 
cuando emerge en plenitud la consistencia de las figuras naturales. Ahora bien, el estudio teológico de la percepción (Wahrnehmung) conduce a una «doctrina de la percepción» (Erblickungslehre) ${ }^{3}$. Esta doctrina presupone la simplicidad (Einfaltung), un neologismo con el que von Balthasar pretende significar una actitud delante del misterio y, en un sentido más profundo, un proceso de concentración teologal sobre la unidad originaria del misterio de $\mathrm{Cristo}^{4}$. De esta forma, para el teólogo suizo la percepción implica una reconfiguración interior, la cual es fruto de las consecuencias de la encarnación y de la pascua.

Por este motivo, la analogía del ser, aunque importante, no constituye lo definitivo de la percepción cristiana del mundo, ya que existe la posibilidad de realizar un paso más, esto es, de captar la dimensión figurativa cristológica y trinitaria del mismo. Para la percepción originada en el evento pascual, habría en el Cristo resucitado una fuerza creadora de figuras (Gestaltunsgkraft; Gestaltungsmacht ${ }^{5}$ ). Según el mismo Hans Urs von Balthasar:

«(es el amor divino) lo que por antonomasia configura y da forma. Es el poder creador de Dios mismo inserto en el hombre a través de la encarnación. Por eso, a la luz de las ideas divinas, el amor es capaz de leer correctamente en el mundo de las formas de la creación, especialmente la del hombre. Al margen de esta luz, el hombre no es más que un jeroglífico incomprensible, contradictorio. Sólo es descifrable a través de la cruz y la resurrección, entendidas como amor y gloria de Dios ensangrentado, abandonado» ${ }^{6}$.

Sin embargo, es interesante notar que la terminología balthasariana incluya una expresión para designar la ausencia o privación de figuras: Umgestalt. Esta expresión significaría la figura deformada que, precisamente, ha perdido su carácter de figura ${ }^{7}$. Tal como lo precisa un comentador:

«...la Palabra hecha carne, en efecto, no solamente llega al silencio de la no-palabra sobre la cruz, sino que con la segunda muerte del descenso a los infiernos pierde además toda posible articulación de palabra (Un-Wort) y de forma (Un-Gestalt), para revelar sólo así el amor absoluto (trinitario) de Dios, que trasciende toda palabra pronunciable y en él todo figura inimaginable (Über-Wort - Über-Gestalt). La continuidad disponible en el misterio pascual es dada por el único amor trinitario del cual él es autoglorificación»8.

La naturaleza es considerada por la estética teológica balthasariana a partir de algunos poetas, teólogos y pensadores — como san Agustín, san Juan de la Cruz, Charles Pèguy y otros-. Todos ellos, en épocas y contextos muy distintos, pusieron de relieve la dimensión epifánica del mundo natural a la

\footnotetext{
3 Fisichela, R., Hans Urs von Balthasar. Amore e credibilità cristiana. Città Nuova editrice, Roma, 1981, 104-105

4 Vignolo, R, op. cit., 485.

5 Ib., 367; 487.

6 Von Balthasar, H. U., Gloria. Una estética teológica. T. 1: La percepción de la forma, Cristiandad, Madrid 1985, 374.

7 Vignolo, R, op. cit., 225-228; 385; 427; 489.

8 Ib., 31.
} 
luz de la figura cristológica9 ${ }^{9}$ En la perspectiva del presente trabajo, interesará mostrar cómo la destrucción ecológica implica una actividad de privación de la configuración teológica de la naturaleza por parte del ser humano. Se destacará así que la conceptualización balthasariana de «figura» natural es fecunda para pensar una situación crítica actual: la crisis ecológica, es decir, la modificación abrupta de los sistemas naturales en la biosfera. Aunque se trate de una alteración ontológica, ésta tiene obviamente consecuencias fenoménicas.

\section{EL FENÓMENO DE LA ALTERACIÓN ECOLÓGICA Y SU RELEVANCIA ESTÉTICA}

La expresión «Antropoceno» se ha generalizado para designar una nueva era geológica, producida por la acción del Homo sapiens ${ }^{10}$. Se trata de un período caracterizado por la alteración del sistema global de la Tierra, es decir: cambio climático, pérdida masiva de biodiversidad, contaminación de la tierra, mar y aire, depredación de la biosfera, erosión y degradación de los suelos, transformación radical de los ecosistemas, etc. La evolución de la biosfera en su conjunto está sufriendo un momento inesperadamente dramático, debido a la acción antrópica potenciada por el desarrollo de la tecnología en los últimos siglos. Por lo tanto, el Antropoceno está produciendo una alteración radical del universo figurativo natural humano. Se trata de una modificación más profunda que las producidas durante los aproximadamente 3.800 millones de años de historia de la biosfera. La mera catalogación de los diversos fenómenos físicos, químicos y biológicos que se están producendo no alcanzan para producir una imagen de conjunto del probable futuro de la situación del planeta. Se puede prever e imaginar un escenario: el de un paisaje empobrecido en su biodiversidad e, incluso, carente de seres humanos. En otras palabras, un futuro de la biosfera — con humanidad o incluso post-humano- puede

$9 \quad$ Resulta interesante notar que la Constitución Gaudium et spes del Concilio Ecuménico Vaticano II, en su $\mathrm{n}^{\mathrm{o}} 39$ incluye un lenguaje figurativo con raíces en el pensamiento bíblico: "Ignoramos el tiempo en que se hará la consumación de la tierra y de la humanidad. Tampoco conocemos de qué manera se transformará el universo. La figura de este mundo, afeada por el pecado, pasa, pero Dios nos enseña que nos prepara una nueva morada y una nueva tierra donde habita la justicia, y cuya bienaventuranza es capaz de saciar y rebasar todos los anhelos de paz que surgen en el corazón humano. Entonces, vencida la muerte, los hijos de Dios resucitarán en Cristo, y lo que fue sembrado bajo el signo de la debilidad y de la corrupción, se revestirá de incorruptibilidad, y, permaneciendo la caridad y sus obras, se verán libres de la servidumbre de la vanidad todas las criaturas, que Dios creó pensando en el hombre». (http://www.vatican.va/archive/hist_councils/ii_vatican_council/documents/vatii_const_19651207_gaudium-et-spes_sp.html).

10 Hay precedentes, en otros términos, como «Noósfera» de Pierre Teilhard de Chardin. Sin embargo, "antropoceno» pone de relieve los efectos del ser humano sobre la biosfera, en especial los más negativos para la supervivencia de la misma, mientras que la expresión teilhardiana resalta solamente el crecimiento de la acción humana en la historia evolutiva del planeta, con una connotación prioritariamente positiva del fenómeno. 
ser razonablemente anticipado a partir de imágenes presentes, tales como la contaminación de ríos, el empobrecimiento de biodiversidad en las ciudades, los océanos transformados en basureros, el vertido de productos químicos en las fuentes de agua, los accidentes nucleares, la destrucción de selvas y bosques con finalidades agropecuarias, etc. Se trata de radiografías del futuro en pequeñas imágenes del presente.

Precisamente, esta idea constituye el subtítulo de un libro del premio Nobel de Literatura Svetlana Alexiévich ${ }^{11}$, en el que se describe la inédita situación posterior al accidente nuclear sucedido en Chernóbil en el año 1985. En uno de sus capítulos, denominado: "Entrevista de la autora consigo misma. Sobre la historia omitida y sobre por qué Chernóbil pone en tela de juicio nuestra visión del mundo», señala:

«El hombre se vio sorprendido y no estaba preparado para esto. No estaba preparado como especie biológica, pues no funcionaba todo su instrumental natural, los sensores diseñados para ver, oír, palpar... los sentidos ya no servían para nada; los ojos, los oídos y los dedos ya no servían, no podían servir, por cuanto que la radiación no se ve y no tiene olor ni sonido. Es incorpórea. (...) El mundo que nos rodeaba, antes amoldable y amistoso, ahora infundía pavor. La gente mayor, cuando se marchaba evacuada y aun sin saber que era para siempre, miraba al cielo y se decía: 'Brilla el sol. No se ve ni humo, ni gases. No se oyen disparos. ¿Qué tiene eso de guerra? En cambio, nos vemos obligados a convertirnos en refugiados.' Un mundo conocido..., convertido en desconocido» ${ }^{12}$.

Lo menos que se puede anticipar, sin riesgo de ensayar una prospectiva carente de fundamentos, es que el panorama estético natural del futuro será mucho más pobre que el presente. Sin embargo, hay voces que contrarían esta afirmación, basándose en una consideración positivista e iluminista de la tecnología, pronosticando un futuro tecnológicamente mejorado, incluso para la naturaleza. Pero inclusive para esas visiones «tecno-optimistas» resulta imposible ignorar las consecuencias ambientales ya presentes, muchas de ellas irreversibles.

\section{UNA ESTÉTICA TEOLÓGICA APLICADA A LA MUTACiÓN ECOLÓGICA}

Algunas teologías de la ecología de raíz bíblica han abordado la cuestión ambiental en forma estética, es decir, considerando la relevancia perceptiva para

11 Alexiévich, S., Voces de Chernóbil. Crónica del futuro, Penguin Random House Editorial, Buenos Aires 2016.

12 Op. cit., 48-49. Hay que recordar que la contaminación más severa ocurrió dentro de la llamada Zona de Exclusión, un área circular alrededor de la planta con un radio de 30 kilómetros que fue declarada no apta para la vida y que permanece aún cerrada a los visitantes. 
la teología de la crisis ambiental ${ }^{13}$. En ese marco de pensamiento, nos interesa señalar algunos temas relevantes. Por una parte, seleccionar un texto del AT a fin de leerlo en la clave de la estética teológica. En segundo lugar, y debido a la originalidad de la imagen divina del cristianismo, destacar la dimensión de debilitamiento de la percepción trinitaria en la biosfera. Finalmente, interesa repensar el lugar del ser humano en su rol de modificación de las condiciones de percepción de la figura natural.

\subsection{El final «des-figurado» (Is 34, 1-7)}

Los profetas integran el tema de la vida de múltiples maneras. Algunos exégetas practican una aproximación ecológica a los textos bíblicos explorando la noción de interconexión ${ }^{14}$. Este concepto resulta fundamental en ecología, donde existe un modelo de doble dirección entre los habitantes y sus hábitats. En los textos bíblicos, el modelo de relaciones es triple: Dios, seres humanos y mundo natural. En particular, el marco teocéntrico de los profetas está dirigido a las relaciones entre Yahvé Israel, así como a las cuestiones sociales y políticas. Pero ellos también describen la profunda y compleja interrelación entre el pueblo de Dios y el resto de su creación, que está estrechamente ligada a su devoción a Yahvé.

Los textos proféticos exhiben una enorme variante de vocabulario, temas y metáforas para referirse a la relación entre las esferas social y natural. Precisamente, así como en muchos de los oráculos de juicio el destino del mundo está inextricablemente unido con el castigo de las trasgresiones humanas, así también la venida de la justicia y rectitud claramente engloba más que el bienestar humano y social.

La consideración de los profetas sobre la relación entre justicia en sociedad y la fecundidad en el mundo natural apunta a su fundamental creencia en un orden divinamente instituido. Este orden no absuelve a las personas de sus responsabilidades. Más bien, los seres humanos, particularmente aquellos que

13 Cf. Berry, T., The Dream of the Earth Serra Club Books, San Francisco, 1988; Vaney, N., «Biodiversity and Beauty», Pacifica 8 (1995) 335-345; MorandinI, S., Teologia ed Ecologia, Morcelliana, Brescia, 2005; Deane-Drummond, C., «Where Streams meet? Ecology, Wisdom and Beauty in Bulgakov, von Balthasar and Aquinas». En: Meisinger, H.; Drees. W.; ZBigniew, L. (editors), Wisdom or Knowledge? Science, Theology and Cultural Dynamics, T\&T Clark International, London-New York 2006, 108-126; BARTHOLOMEOs I, Nostra madre terra, Qiqajon, Comunità di Bose, Magnano (BI) 2015; Florio, L., «Creación y mundo sacramental. ¿Es hoy posible una visión simbólica y sacramental de la creación? Reflexiones a partir de la mutación planetaria y de la variación perceptiva», Communio (arg.), 1 (1998) 61-72; Iв., Teología de la vida en el contexto de la evolución y de la ecología, Ágape, Buenos Aires 2015. Asimismo, ha habido una recepción en el campo oficial católico: Cf. Francisco, Laudato si', Editrice Vaticana, Vaticano, 2015, $n^{\circ} 84-86$.

14 Marlow, H., «Justice for Whom? Social and Environmental Ethics and the Hebrew Prophets", en: Ethical and Unethical in the Old Testament. God and Humans in Dialogue, T \& T Clark International, Nueva York (2010) 103-121. 
tiene posiciones de poder o influencia, son considerados responsables por la descomposición tanto social como ambiental. El bienestar del pobre, pero también el del mundo mismo, parecería radicar en sus manos.

Seleccionamos un pasaje de Isaías cargado de imágenes y vocabulario de fuerte impacto en una lectura contemporánea.

Is. 34

1 ¡Acérquense, naciones, para oír, pueblos, presten atención!

1 ¡Escuche la tierra y todo lo que hay en ella,

1 el mundo y todo lo que él produce!

2 Porque el Señor está irritado contra todas las naciones

2 y enfurecido contra todos sus ejércitos:

2 los ha consagrado al exterminio,

2 los ha destinado a la matanza.

3 Sus víctimas son arrojadas afuera,

3 de sus cadáveres sube el hedor,

3 y con su sangre se disuelven las montañas.

4 Se diluye todo el ejército del cielo,

4 los cielos son enrollados como un pliego,

4 y todo su ejército se marchita

4 como se marchita el follaje de la vid,

4 como cae marchita la hoja de la higuera.

5 Porque mi espada se abrevó en el cielo:

5 miren cómo baja sobre Edóm,

5 sobre el pueblo que he condenado al juicio.

6 La espada del Señor está llena de sangre,

6 impregnada de grasa,

6 de la sangre de corderos y chivos,

6 de la grasa de riñones de carneros.

6 Porque el Señor tiene un sacrificio en Bosrá,

6 una gran matanza en el país de Edóm.

7 Caen los búfalos con los terneros cebados,

7 los novillos con los toros:

7 su tierra se abreva con sangre,

7 su suelo se impregna de grasa.

8 Porque es un día de venganza para el Señor,

8 un año de desquite para la causa de Sión.

9 Sus torrentes se transformarán en resina

9 y su suelo en azufre;

9 su tierra se convertirá en resina ardiente,

10 que no se extinguirá ni de día ni de noche:

10 la humareda subirá incesantemente.

10 Quedará desierta de generación en generación,

10 nunca más pasará nadie por allí. 
11 Se adueñarán de ella el pelícano y el erizo,

11 la lechuza y el cuervo habitarán allí.

11 Se extenderá sobre ella la plomada del caos

11 y el nivel del vacío.

12 Los nobles no proclamarán más un rey

12 y todos sus príncipes serán aniquilados.

13 En sus palacios crecerán zarzas,

13 en sus fortalezas, ortigas y espinas;

13 será una morada de chacales,

13 una guarida de avestruces.

14 Las fieras del desierto se juntarán con las hienas,

14 los sátiros se llamarán unos a otros.

14 Allí también descansará Lilit

14 y tendrá un lugar de reposo.

15 Allí anidará la serpiente y pondrá sus huevos,

15 los incubará y los hará empollar;

15 y allí también se reunirán los buitres,

15 cada uno con su pareja.

16 Consulten el libro del Señor y lean:

16 no falta ninguno de ellos,

16 ni uno solo ha perdido su pareja,

16 porque lo ha mandado la boca del Señor

16 y su espíritu los ha congregado.

17 Él mismo ha echado la suerte para ellos,

17 su mano les asignó una parte con la cuerda:

17 ellos la poseerán para siempre,

17 habitarán allí de generación en generación.

Este poema presenta con vigor imaginativo una visión trágica y sombría. Se trata de la ejecución de un juicio solemne y de sus fatídicas consecuencias. Entre los extremos del poema se describe la destrucción del reino, que se convierte en morada lúgubre de las fieras de más prestigio: machos cabríos, búfalos y toros.

El texto presenta un escenario que no es absolutamente desconocido a la ecología contemporánea ${ }^{15}$. Se describe, en cierto modo, un proceso de perturbación y degradación ambientales. El juicio, precisamente, comienza describiendo el deterioro físico de la tierra (vv. 9-10). A diferencia de otros pasajes similares (Is 13 y Jr 50) en los que se describe la aniquilación de poblaciones, aquí hay destrucción del ambiente, incluyendo el suelo (v. 9).

La quema de la tierra y la degradación del suelo llevan el lugar hacia la desertificación y el despoblamiento de las áreas rurales (v. 10). La naturaleza desolada de la tierra, vacía de pastos, agricultura, animales domésticos, es

15 Cf. Ib., 114. 
subrayada en el v. 11 por: «vacío de forma» y «vacuidad» (traducción utilizada: «Se extenderá sobre ella la plomada del caos y el nivel del vacío»).

Estas dos expresiones se encuentran juntas también en Gn 1,2, donde se describe el estado de pre-creación, lo cual puede sugerir que Is 34 esté expresando que se está deshaciendo el orden creado. El hebreo expresa con

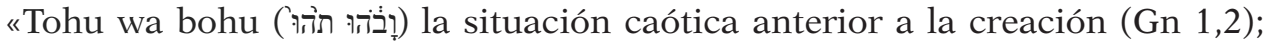
desaparecen los nombres, los hombres vuelven al vacío Se sugiere la idea de un desandar la creación, como una vez en el diluvio, aunque con límites ${ }^{16}$. De todos modos, aquí la devastación no es la de todo el orden creado, sino sólo de una sección: aquella de la civilización o sociedad humana. Sin embargo, junto a ello e, implícitamente a causa de ello, la degradación del suelo y la destrucción del paisaje físico es la despoblación y la desestabilización de los asentamientos (vv. 11b-23). El abandono de la ciudad y del campo por parte de sus habitantes proporciona el alcance para el desarrollo de un ambiente ecológico alternativo en el que los animales salvajes tomen residencia (11 ${ }^{\mathrm{a}}$ y $\left.13 \mathrm{~b}-15\right)$.

La nueva situación será permanente (v.10: «día y noche», "por siempre»). Desde el punto de vista de la población humana, la situación es catastrófica, pues los animales salvajes tomarán posesión de la tierra que ésta habitaba. Sin embargo (vv.16b-17 a), esta atención por esos animales por parte de Dios ya estaba prevista.

El texto sugiere una cierta teología de los animales. En una primera lectura, daría la impresión de que los animales salvajes son un signo del castigo divino. Sin embargo, el conjunto de los libros bíblicos señala que todos los seres son expresión del amor creador de Dios, aun cuando el pecado humano haya añadido una nota adicional de caos en el proceso de la vida. La Biblia contiene una axiología positiva de la estructura ontológica del universo; por ello, no hay elementos del universo - tampoco animales - cuya entidad sea calificada como ontológicamente negativa. Lo que hace patente, en cambio, es la amenaza del caos (el tohu wa bohu) en la historia de la vida por obra de la desmesura humana, la cual distorsiona un proceso en el que los seres vivientes son signos del amor creador y conservador de Dios, tal como resaltan Gn 1 y el Sal 8.

Desde el punto de vista ecológico, la desolación y el despoblamiento humano del territorio urbano ha permitido el florecimiento de otra parte del orden creado. El despliegue de la venganza de Yahvé contra la humanidad desplaza el equilibrio ecológico a favor del mundo no humano. El sentido explícito del propósito y plan divino previene de la idea antropocéntrica de que el bienestar humano es lo único que importa. El poder del mundo natural por el cual la tierra revierte hacia su pasado y es colonizada por los animales salvajes, recuerda entonces y ahora que los asentamientos humanos y el cultivo no es el modo defectuoso del ambiente ${ }^{17}$.

16 Cf. Alonso Schökel, L, Sicre Díaz, J. L, Profetas. Comentario I, Cristiandad, Madrid, 1980, 246.

17 Cf. Marlow, H., op. cit., 116. 
Al poema le sigue otro con una visión antagónica, puesto que presenta el regreso a Sión con imágenes de restauración y, por lo tanto, de «reconfiguración» (Is 35).

\subsection{La pérdida de las dimensiones trinitarias del cosmos}

En el pensamiento bíblico, la creación es entendida como un primer momento de un proceso de índole salvífico ${ }^{18}$. La entera historia del universo está relacionada con un propósito soteriológico. En particular, para el cristianismo, ese designio se concreta en la figura de Cristo. ${ }^{19}$ Sin embargo, la naturaleza continúa manteniendo su valor como expresión de la presencia divina. Se trata del lenguaje divino en su propia creación que no se contrapone al lenguaje de la revelación. Von Balthasar señalaba que:

«la revelación en el ser no se puede dejar a un lado sin más para correr en pos de la revelación de la gracia y de la palabra más elevada y, por ello mismo, considerada como la única importante. El hombre aprende ante todo como criatura a conocer al Dios cada vez mayor y, por consiguiente, cada vez más oculto, como su Señor» ${ }^{20}$.

Ahora bien, el NT aportó una imagen enriquecida de Dios. Se trata de un Dios trinitario, dentro de su unicidad y trascendencia. La percepción de fe del creyente bíblico cristiano se focaliza en la figura unitrina de Dios. Desde allí remite su percepción hacia su entorno creado, procurando percibir las figuras naturales a la luz de aquella su fuente creadora. Por ese motivo, la teología cristiana concibió, desde sus primeros siglos, la idea de una creación impregnada por la figura trinitaria. Con este criterio, desarrolló concepciones teológicas tales como las de las semillas del Verbo o de la cristología cósmica ${ }^{21}$, o la de los vestigios trinitarios en la creación. Habría, pues, una configuración cristológica y trinitaria del cosmos, discernida por un creyente que ha sido «informado» -reinstalando su programa perceptivo, en lenguaje cibernético ${ }^{22}$ - mediante la figura o Gestalt cristológica y trinitaria. En efecto, para la teología cristiana la encarnación y la pascua han reconfigurado la relación del mundo con su raíz trinitaria, lo que es percibido por la visión de la fe. Sin embargo, esta mirada no

18 Cf. LÖNING, KARL; ERICH ZENGER, In principio Dio creó. Teologie bibliche della creazione, Queriniana, Brescia, 2006; Conradie, Ernst M. (editor), Creation and Salvation, Vol 2: A Companion on Recent Theological Movements, Studies on Religion and the Environment. Münster: LIT Verlag, Münster, 2012.

${ }_{19}$ En el lenguaje de Pierre Teilhad de Chardin, la cosmogénesis, biogénesis y noogénesis culmina en la cristogénesis y, finalmente, en el Punto Omega (Cf. NuÑEZ DE CASTRo, I.: «The BioPhilosophy of Teilhard de Chardin». En: Del Riego, H. (ed.): God Seen by Science: Anthropic Evolution of the Universe, Universidad Pontificia de Comillas, Madrid, 2008, 99-126).

20 Von Balthasar, H. U., Gloria. Una estética teológica. T. 1: La percepción de la forma, Cristiandad, Madrid 1985, 400.

21 Cf. Papanicolau, Jorge, Cristología cósmica, Epifanía, Buenos Aires, 2005.

22 La expresión está en: García Andrade, C., La Trinidad: «sotfware» de Dios. Reinstalando a Dios en la cultura occidental, Ciudad Nueva, Madrid, 2000. 
excluye el ejercicio necesario de la integración con otras perspectivas aportadas por las diversas ciencias y disciplinas ${ }^{23}$. Sólo bajo esta integración sería posible captar los diversos lenguajes emergentes de una biosfera creada, encarnada por el Verbo, animada por el Espíritu, pero también maltratada y desfigurada de una manera inusitada por el ser humano.

Desde este marco conceptual, algunas líneas teológicas contemporáneas han reflexionado sobre la pérdida de rasgos de la gloria de Dios en el mundo natural durante el período del Antropoceno ${ }^{24}$. Así, por ejemplo, la disolución de especies biológicas implicaría una disminución figurativa y, por ello, una pérdida perceptiva de la gloria de Dios en su creación. Se trata de la pérdida de formas figurativas comunicativas de rasgos del Dios creador con consecuencias presentes y futuras. Las extinciones de especies y ecosistemas implican que algo de la sabiduría y hermosura divinas o bien desaparece para siempre o bien se opaca. Desde la perspectiva del NT, se añade que lo que se pierden son rasgos de la acción del Dios trinitario. Efectivamente, tal como fue leído desde Tertuliano y san Agustín en adelante, la naturaleza lleva en sí vestigios de su creador, el cual es un misterio de comunión conformado por tres quiénes, intrínsecamente unidos, pero distintos entre sí. Son, pues, aspectos de esa identidad trinitaria los afectados por la disolución de las formas de los seres vivientes y los paisajes. En efecto, los rasgos del poder creador del Padre, la lógica y belleza del Hijo, el amor unitivo del Espíritu, son alterados en esta mutación ontológica y, por lo tanto, también fenoménica.

\subsection{El ser humano: ¿desfigurador, re-configurador, transfigurador?}

La conceptualización mediante el término «Antropoceno» permite situar el corazón del conflicto figurativo teológico respecto de la naturaleza. Es el ser humano, la figura humana, el responsable de la alteración estética. En efecto, desde el punto de vista perceptivo, el Homo sapiens aparece con una notable capacidad de desfiguración del ámbito en el que habita. Es cierto que el mismo proceso evolutivo es, de por sí, un fenómeno de extinción y aparición de nuevas especies $^{25}$. Sin embargo, la actividad antrópica ha acelerado notablemente los tiempos y está sometiendo la biosfera a una presión que puede generar una desfiguración catastrófica del paisaje biológico.

23 Cf. Avenatti de Palumbo, C. - Florio, L., "Lenguajes en palimpsesto: teología/poesía/ ciencia/mística», en: Sociedad Argentina de Teología, Discursos científicos y discursos teológicos. Creer en el contexto de los nuevos saberes. XXXI ${ }^{\mathrm{a}}$ Semana de Teología, Ágape, Buenos Aires, 2013, 359-372.

24 Cf. Florio, Lucio, "Trinitarian Perspectives on Ecology». Studia Aloisiana. 6, 3 (2015) 17-31. (http://tftu.sk/studiaaloisiana/wp-content/uploads/2015/10/Florio_3_2015.pdf).

25 Para una relación entre evolución y ecología en el contexto de un debate ético, cf.: Zognong, Dieudonné,. "L'évolutionnisme est-il compatible avec l'éthique écologique?» Quaerentibus. Teología y ciencias, 4 (2014) 4-15 (http:/quaerentibus.org/quaerentibus/ DQ_04i.pdf). 
Al enmarcar teológicamente la cuestión ecológica, se puede pensar que existe una fuerza interna más allá de la evolución de la vida, generadora de una novedad figurativa en la biosfera. Se trata de la fuerza cristológica y pneumatológica. En efecto, para la visión del NT, el misterio de Cristo, con posterioridad a su pascua, afecta al ser humano y, a través suyo, al resto de la creación (cfr. Rom 8, 19-22). Además, la actividad soteriológica prosigue su curso mediante la acción del ser humano, quien puede extender el dinamismo redentor al resto del universo. Los textos neotestamentarios emplean una pluralidad de expresiones para designar la novedad producida por el acontecimiento de Cristo $^{26}$, entre las cuales: «nueva criatura» (Gál 6,15) y «nueva creación» (Rom 6,4). Con ellos se quiere significar la aparición de un universo figurativo absolutamente novedoso, por un lado homogéneo y por otro heterogéneo con la primera creación. Ahora bien, la visión del NT atribue al Espíritu Santo el rol de vivificar al hombre y al mundo. Su actividad renovadora es la que anima la novedad en el mundo humano y el universo perceptivo. De este modo, es posible atribuir al ser humano no sólo un rol desfigurador — anómico, dispersivo, destructor — sino también configurador, como mediador, de un universo gestáltico cristológico y pneumático.

\section{ConcLusión}

El período del Antropoceno, al alterar las estructuras físicas, químicas y biológicas del planeta, está provocando un proceso de variación estética prodigiosa. Esta mutación es en gran medida destructiva de realidades biológicas o relacionales (especies, ecosistemas) mediante un poderoso mecanismo de «des-figuración», cuya responsabilidad es primariamente humana. Se trata, perceptivamente, de una aniquilación figurativa (Umgestalt). Ante la profunda modificación perceptiva del planeta, es legítimo preguntarse acerca de la probablidad o no de que el ser humano — simultáneamente el Homo sapiens biológico y el Imago Dei teológica - pueda detener tal dinámica desfigurativa del panorama natural. El aporte bíblico integra para los creyentes la convicción de la existencia de una acción reconfiguradora del cosmos y de la vida por parte de Cristo y del Espíritu ${ }^{27}$. En todo caso, el futuro inmediato parece destinado a un empobrecimiento figurativo de la naturaleza de dimensiones impredecibles, ligadas a la acción humana que incluye también la inercia de procesos ya iniciados. La estética teológica aporta elementos para pensar tal escenario así como para considerar más profundamente el valor perceptivo de la naturaleza, inherente al mismo pensamiento bíblico. Evidentemente, lo perceptivo reenvía

26 Cf. Söding, Gerardo José, La novedad de Jesús. Realidad y lenguaje en proceso pascual, Ágape, Buenos Aires, 2012.

27 García Doncel, Manuel, «The Word as Design-Realiser for the Creation, and the Spirit as Disorder-Restorer for the New Creation». En: ESSSAT, Studies in Science \& Theology, $\mathrm{n}^{\circ} 8$ (2002) 43-75. 
hacia lo ontológico: hay pérdida figurativa por realmente existe destrucción y alteración de la biosfera. En todo caso, la estética teológica ayuda a mirar más profundamente las dimensiones del proceso a fin de pensar desde la propia tradición creyente - intransferible, sin embargo, a no creyentes- el valor de la biosfera de la que se forma parte.

\section{BiBLIOGRAFÍA}

Alexiévich, S. (2016). Voces de Chernóbil. Crónica del futuro, Penguin Random House. Editorial, Buenos Aires, 2016.

Alonso Schökel, L., Sicre Díaz, J. L. (1980). Profetas. Comentario I. Madrid: Cristiandad. Avenatti de Palumbo, C., Florio, L. (2013). «Lenguajes en palimpsesto: teología/poesía/ ciencia/mística», en: Sociedad Argentina de Teología, Discursos científicos y discursos teológicos. Creer en el contexto de los nuevos saberes. XXXI ${ }^{a}$ Semana de Teología. Buenos Aires: Ágape, 359-372.

Bartholomeos I (2015). Nostra madre terra, Qiqajon, Comunità di Bose, Magnano (BI). Berry, T. (1988). The Dream of the Earth Serra Club Books, San Francisco.

Conradie, E. M. (editor) (2012). Creation and Salvation, Vol 2: A Companion on Recent Theological Movements, Studies on Religion and the Environment. Münster: LIT Verlag, Münster.

Deane-Drummond, C. (2006). «Where Streams meet? Ecology, Wisdom and Beauty in Bulgakov, von Balthasar and Aquinas». En: Meisinger, Hubert; Willem B. Drees; Liana Zbigniew (editors), Wisdom or Knowledge? Science, Theology and Cultural Dynamics, T\&T Clark International, London-New York, 108-126.

— , Eco-Theology, Darton, Longman and Todd. London. 2008

Fisichela, R. (1981). Hans Urs von Balthasar. Amore e credibilità cristiana. Roma: Città Nuova editrice.

Florio, L. (1998). «Creación y mundo sacramental. ¿Es hoy posible una visión simbólica y sacramental de la creación? Reflexiones a partir de la mutación planetaria y de la variación perceptiva», Communio (arg.), 1 (1998) 61-72.

-, «Una creación evolutiva y una biosfera amenazada», Estudios Trinitarios, 46, 1 (2012), 105-143.

— , (2015). «Trinitarian Perspectives on Ecology». Studia Aloisiana. 6, 3, 17-31. (http:// tftu.sk/studiaaloisiana/wp-content/uploads/2015/10/Florio_3_2015.pdf).

- , (2015). Teología de la vida en el contexto de la evolución y de la ecología. Buenos Aires: Ágape.

Francisco (2015). Laudato si', Editrice Vaticana, Vaticano.

García Andrade, C. (2000). La Trinidad: «sotfware» de Dios. Reinstalando a Dios en la cultura occidental. Madrid: Ciudad Nueva.

García Doncel, M. (2002). «The Word as Design-Realiser for the Creation, and the Spirit as Disorder-Restorer for the New Creation». En: ESSSAT, Studies in Science \& Theo$\log y, \mathrm{n}^{\circ}$ 8, University of Aarhus, Aarhaus, 43-75.

Lona, H. (2008). ¿Qué es el hombre para que te acuerdes de él? Buenos Aires: Claretiana. Löning, K.; Erich Z. (2006). In principio Dio creó. Teologie bibliche della creazione. Brescia: Queriniana. 
Marlow, H. (2010). «Justice for Whom? Social and Environmental Ethics and the Hebrew Prophets», en: Ethical and Unethical in the Old Testament. God and Humans in Dialogue. Nueva York: T \& T Clark International, 103-121.

Moltmann, J. (2011). «The Future of Creation», en: Trafny, Tomasz; Puig, Armand (editado por), God and World. Theology of Creation from Scientific and Ecumenical Standpoints. Vaticano: Libreria Editrice Vaticana, 65-80.

Morandini, S. (2005) Teologia ed Ecologia. Brescia: Morcelliana.

Nuñez de Castro, I. (2008). «The Bio-Philosophy of Teilhard de Chardin». En: Del Riego, H. (ed.): God Seen by Science: Anthropic Evolution of the Universe. Madrid: Universidad Pontificia de Comillas, 99-126.

Papanicolau, J. (2005). Cristología cósmica. Buenos Aires: Epifanía.

Schaefer, J. (2001). «Appreciating the Beauty of Earth», Theological Studies (62: 1), March, 23-52.

Söding, G. J. (2012). La novedad de Jesús. Realidad y lenguaje en proceso pascual. Buenos Aires: Ágape.

Vignolo, R. (1982). H.U.von Balthasar: Estetica e singolarità, Istituto Propaganda Libraria, Milano.

Von Balthasar, H. U. (1985). Gloria. Una estética teológica. T. 1: La percepción de la forma. Madrid: Cristiandad. (Original: Herrlichkeit, Johannes Verlag, Einsiedeln, 1961).

—, (1998). «El lenguaje de Dios», Proyecto, 30, 43-69. (Original: «Die Sprache Gottes», Hans Urs von Balthasar. Premio Internazionale Paolo VI, 1984, Notiziario 8, 1984.

Vaney, N. (1995). «Biodiversity and Beauty», Pacifica 8, 335-345.

Zognong, D. (2014). "L'évolutionnisme est-il compatible avec l'éthique écologique?» Quaerentibus. Teología y ciencias, 4, 4-15 (http://quaerentibus.org/quaerentibus/ DQ_04i.pdf).

Pontificia Universidad Católica de Argentina

LUCIO FLORIO

lflorio.18@gmail.com

[Artículo aprobado para publicación en diciembre de 2016] 